\title{
Promotional Role of Lymphoid Nodules in Colorectal Cancer: Implica- tions for Endoscopic Screening and Prevention
}

\author{
Ivan L. Cameron*
}

Department of Cellular and Structural Biology, University of Texas Health Science at San Antonio, San Antonio, Texas 78229-3900, USA

\begin{abstract}
This report examines the anatomical distribution of colorectal cancer CRC in the human large bowel. The findings indicate the high occurrence of cancer in the rectum. The reason for the high incidence of rectal cancer is explored. Published data were compiled and analyzed to correlate the high occurrence of CRC in the human rectum to the high occurrence of lymphoid nodules (LNs). Histopathologic classification and distribution of CRC types was reviewed. Statistical findings reveal a significant $(\mathrm{p}<0.01)$ positive relationship between number of LNs and number of CRCs. Histopathological findings indicate that LNs promote epithelial hyperplasia and a nonpolyploid pathway of cancer development especially in the rectum. The findings of a 7 to 8 fold higher density of rectal cancer per $\mathrm{cm}$ length in the human rectum compared to the other segments of the large bowel emphasize the importance of careful endoscope screening for the detection of nonpolyploid rectal cancers. Review of human and rat literature suggests that drugs that suppress the immune system and that aspirin, an anti-inflammatory agent,may work to reduce risk of CRC via their effect on lymphoid nodules.
\end{abstract}

Keywords: Colorectal cancer, lymphoid nodules, CRC promotion, CRC prevention, rectal cancer, endoscopy.

\section{INTRODUCTION}

This report examines: the anatomical distribution of CRCs and summarizes evidence that lymphoid nodules promote de novo CRC in rats and in the rectum of humans. Implications for CRC endoscopic screening and for CRC prevention are discussed.

\section{ANATOMIC DISTRIBUTION OF HUMAN COLO- RECTAL CANCERS}

CRC is not uniformly distributed through the large bowel as summarized in Table 1 [1-26]. The right or proximal side (consisting of cecum, ascending and transverse sections) is affected by cancer less frequently than the left or distal side (consisting of descending, sigmoid and rectum sections). On average, the left side is demonstrated to have more than twice the number of cancers as the right side.

The CRC incidence values reported in Table $\mathbf{1}$ are the general values reported in each study. Factors such as age, gender, ethnicity, or time of study are not factored into the incidence values reported in Table $\mathbf{1}$. Table $\mathbf{1}$ indicates the study site of each report as well as the rectal incidence values, in parenthesis, from those studies where reported. Available data on study sample size (number in study) is also reported in Table $\mathbf{1}$.

Fig. (1) summarizes the date in Table $\mathbf{1}$ and illustrates difference in the distribution of $\mathrm{CRC}$ in the large bowel. The mean \pm SE percent of CRCs in each location is: Right 27.84 \pm 1.48 , Left $71.97 \pm 1.51$, Rectum $39.60 \pm 2.73$, Left minus Rectum $31.96 \pm 1.99$. An analysis of variance of these data

*Address correspondence to this author at the Department of Cellular and Structural Biology, University of Texas Health Science at San Antonio, San Antonio, Texas 78229-3900, USA; Tel: 210-567-3817; Fax: 210-567-3803; E-mail: Cameron@uthscsa.edu followed by a multiple range test indicates the left side is about two fold significantly higher $(\mathrm{p}<0.001)$ than the other locations. The rectum is significantly higher than either the Right or the Left minus the Rectum ( $\mathrm{p}>0.001)$.

These CRC distribution data, when expressed per $\mathrm{cm}$ length of each location, reveal a telling fact. Given the average lengths of large bowel segments are: Right $67 \mathrm{~cm}$, Left $78 \mathrm{~cm}$, Rectum $12 \mathrm{~cm}$ and Left minus rectum $66 \mathrm{~cm}$ and dividing by the mean percent of tumors in each of these four segments by the $\mathrm{cm}$ length values gives the percent of all CRC's per cm along the length of the large bowel. The percent values obtained by this procedure, as illustrated in Fig. (2), are: Right $0.42 \% / \mathrm{cm}$, Left $0.92 \% / \mathrm{cm}$, Rectum $3.30 \% / \mathrm{cm}$, Left minus rectum $0.48 \% / \mathrm{cm}$. Thus one can expect 6.9 to 7.8 times more cancers per $\mathrm{cm}$ length of rectum than elsewhere in the large bowel. This finding emphasizes the importance of careful endoscopic screening of the rectum for detection of CRCs.

\section{CONGRUENCE IN DISTRIBUTION OF CRC AND LYMPHOID NODULES (LN'S) IN THE LARGE BOWEL}

This section of the report shows research results from large bowel carcinogen induced CRC in animal models that has led to a more complete understanding of CRC distribution in humans.

Fig. (3), from Hardman and Cameron, summarizes results of three past studies on the CRC distribution in the large bowel following injection of a CRC inducing carcinogen in rats [27]. In these studies, a large bowel carcinogen was administered followed by a period of time before sacrifice. The occurrence of large intestinal lesions was scored as percent of the distance from the anus to the ileum. Histopathology of each lesion was done to confirm if the lesion was 
Table 1. Distribution of Colorectal Cancers Expressed as Percent of Total Number of Right and Left Sided Cancers. Rectal Subsite Values Reported in Parentheses

\begin{tabular}{|c|c|c|c|c|c|}
\hline Right & Left (Rectum) & Study Site & Reference & Year & Number in Study \\
\hline 40 & $60(15)$ & Los Angeles & Morgenstern and Lee [1] & 1978 & 1,009 \\
\hline 39 & $61(28)$ & New York & Fleshner et al. [3] & 1989 & 922 \\
\hline 42 & $58(29)$ & US & Cooper et al. [5] & 1995 & 75,266 \\
\hline 36 & $64(41)$ & US & Qing et al. [6] & 2009 & 690 \\
\hline 33 & $67(48)$ & US & Wu et al. [7] & 2004 & 336,798 \\
\hline 28 & $72(29)$ & West India & McFarlane et al. [10] & 2004 & 132 \\
\hline 31 & 69 & UK & Gomez et al. [11] & 2004 & 771 \\
\hline 32 & $68(37)$ & UK & UK@Cancer Stats & 2010 & 62,896 \\
\hline 28 & 72 & N. Ireland & Crerand et al. [12] & 2001 & 5,153 \\
\hline 33 & $67(33)$ & N. Ireland & McCallion et al. [13] & 2001 & 4,931 \\
\hline 33 & $67(39)$ & Scandinavia & Eide [15] & 1986 & \\
\hline 23 & $77(38)$ & Netherlands & van Rossum et al. [14] & 2008 & 185 \\
\hline 14 & $86(55)$ & Iran & Nikshoar et al. [20] & 2006 & 2,107 \\
\hline 24 & $76(67)$ & India & Deo et al. [21] & 2001 & 91 \\
\hline 26 & 74 & India & Peedikayil et al. [22] & 2009 & 220 \\
\hline 36 & $64(36)$ & New Zealand & Jass [23] & 1991 & 15,395 \\
\hline 25 & $75(24)$ & Japan & Sakamoto et al. [24] & 2006 & 565 \\
\hline 34 & $66(27)$ & Japan & Goto [25] & 2006 & 14,817 \\
\hline 24 & 76 & Japan & Fu et al. [26] & 2005 & 1,324 \\
\hline 26 & $74(54)$ & China & Qing et al. [6] & 2009 & 870 \\
\hline 11 & 89 & China & Leng et al. [27] & 2010 & 4,450 \\
\hline 22 & $78(51)$ & Taiwan & Shieh et al. [29] & 1990 & 1,198 \\
\hline 20 & $80(53)$ & Korea & Kim et al. [28] & 2000 & 4,129 \\
\hline
\end{tabular}




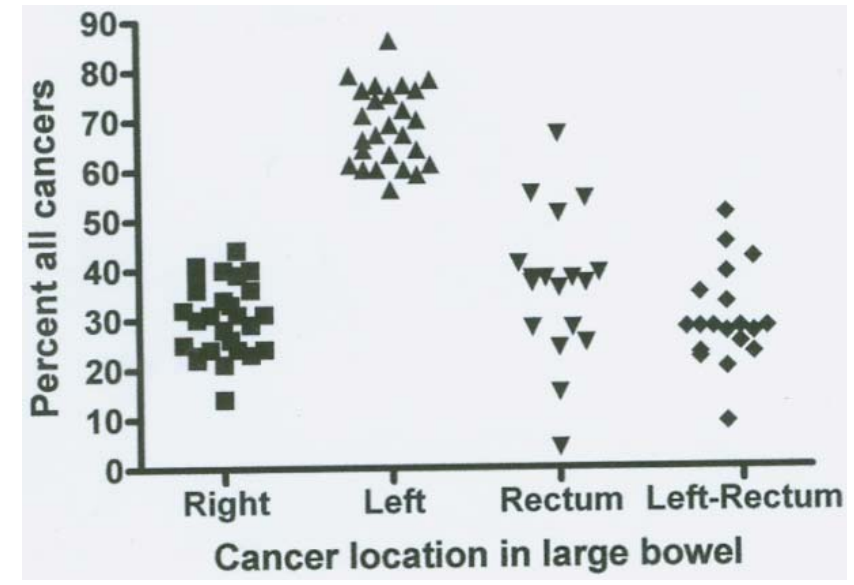

Fig. (1). Graph summarizing distribution of percent of all CRC's located in different locations in the large bowel (data from Table 1). Statistical analysis reveals the incidence of CRC is significantly higher in the left side of the large bowel than other locations but no other significant differences.

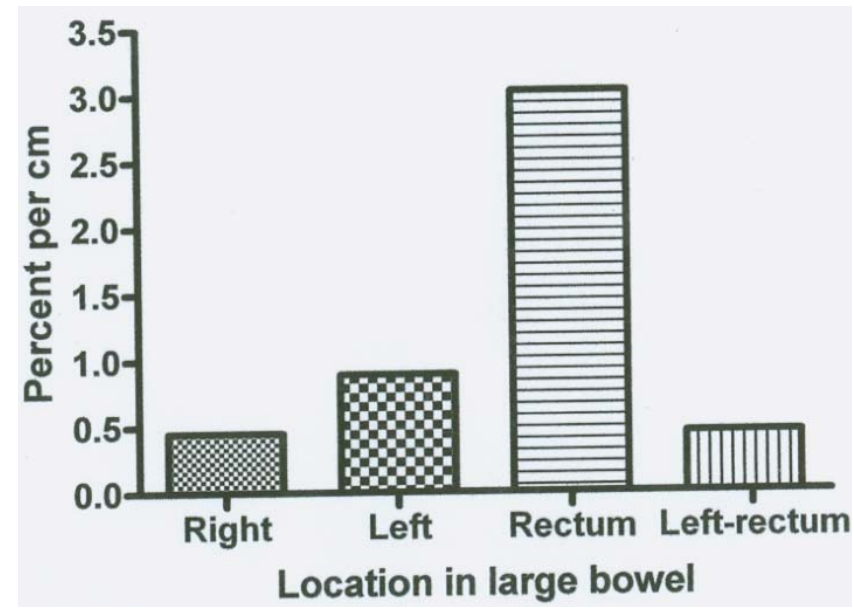

Fig. (2). Bar graph of mean incidence of CRC's (from Table 1) expressed per $\mathrm{cm}$ length of each large bowel section. This graph illustrates there are 7-8 times more CRC per $\mathrm{cm}$ of rectum than elsewhere in the large bowel.

a carcinoma or adenoma. The data in Fig. (3) is limited to carcinoma distribution [27-30]. The results of each of the three reported studies reveal a trimodel distribution of CRC along the length of the rat large bowel.

What could be responsible for this trimodel distribution of CRC? The study of Nauss et al. reported on the distribution of: carcinomas (polyploid and sessile types), adenomas and aggregates of lymphoid nodules (ALN) along the length of the rat large bowel [28]. A linear regression analysis of their data was reported by Cameron et al. [33]. The distribution of ALN scored at the time of sacrifice of the DMHtreated rats, was significantly correlated with the distribution of the more sessile cancers but was not significantly correlated with the less numerous polyploid cancers or adenomas. The significant correlation between carcinogen (DMH) induced CRC and the location of ALN in rats was confirmed by Hardman and Cameron 1994 [30]. Carter et al. also reported a significant positive linear regression relationship between the numerical distribution of $\mathrm{LN}$ and the numerical distribution of CRC in the large bowel of DMH treated mice [31].

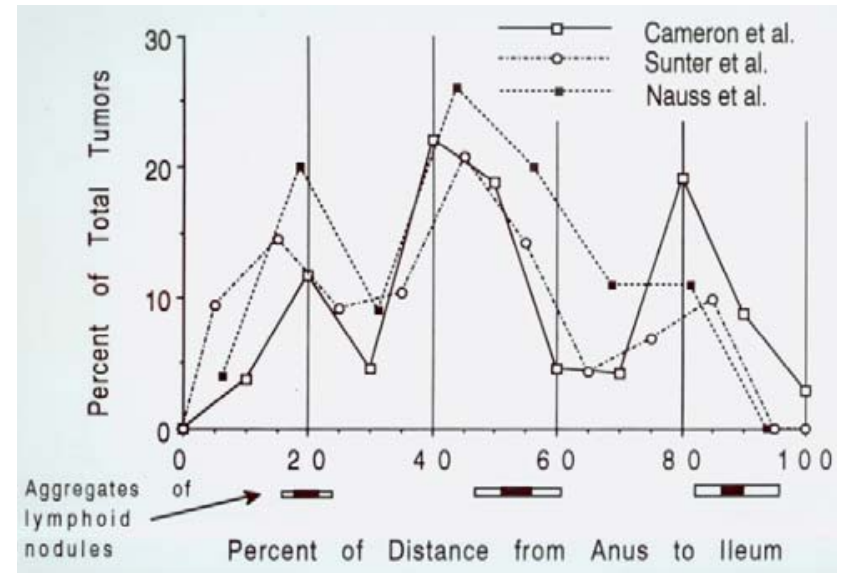

Fig. (3). Graphs the percent of the total number of CRC's found in rats treated with a large bowel carcinogen as a function of percent of distance from anus to illeum. The data are form three previous experiments [28-30]. The location of aggregates of lymphoid nodules (ALN) of 20 non-colon carcinogen treated rats is indicated by bars along the horizontal axis of the graph. No solitary LN's were found between the ALN's. This graph shows correlation in occurrences of CRC and location of ALN. This correlation is significant (see text). Graph reproduced from reference ${ }^{27}$ with permission of Oxford University Press.

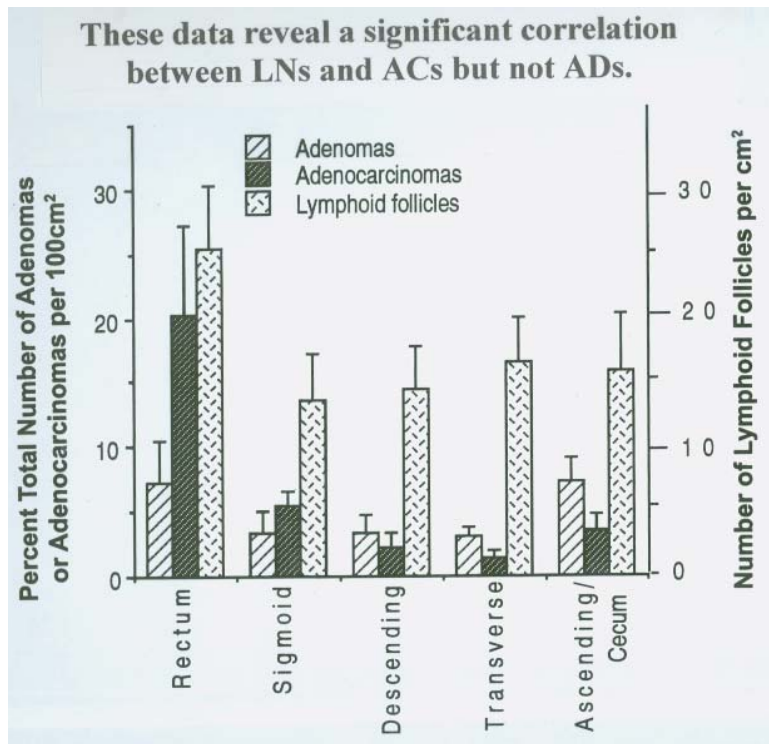

Fig. (4). The anatomic distribution of adenomas (AD) adenocarcinomas (AC) and lymphoid nodules (LN's) in the human large bowel. The results from multiple sources were gathered and evaluated $[14,42]$. The findings are expressed per $\mathrm{cm}^{2}$ of macroscopic surface. The number of LN's and AC's but not AD's was significantly higher in the rectum than elsewhere in the large bowel. The linear regression of the five bowel segments reveals significant correlation between LN's and AC's but not between LN's and AD's.

There is also evidence in support of a significant correlation between the numerical distribution of CRC and of $\mathrm{LN}$ in humans. The data in Fig. (4) gives information on the nu- 
merical distribution of adenomas, CRC [14,32] and LN's [33] in various segments along the length of the large bowel. Linear regression analysis of the mean values from each bowel segment indicates a significant linear correlation between numerical density of LN and CRC ( $p<0.05)$ but not of adenomas ( $p>0.05)$.

As reported above there is a 7-8 fold higher incidence of CRC per $\mathrm{cm}$ length in the human rectum than elsewhere in the large bowel. A careful study of number of LN along the length of the rectum and the lower segment of the sigmoid colon in five human cadavers [34] was correlated with the incidence of CRC in the same region of the large bowel in 50 patients diagnosed with CRC in the rectum and lower segment of the sigmoid colon [35]. Endoscopic measurements indicated the location of each CRC up to a distance of $22 \mathrm{~cm}$ above the anal verge. Fig. (5) summarizes the LN and CRC results of this study. Linear regression analysis of the number of LN's vs. the incidence of CRC indicated a significant linear correlation $(\mathrm{p}<0.01)$.

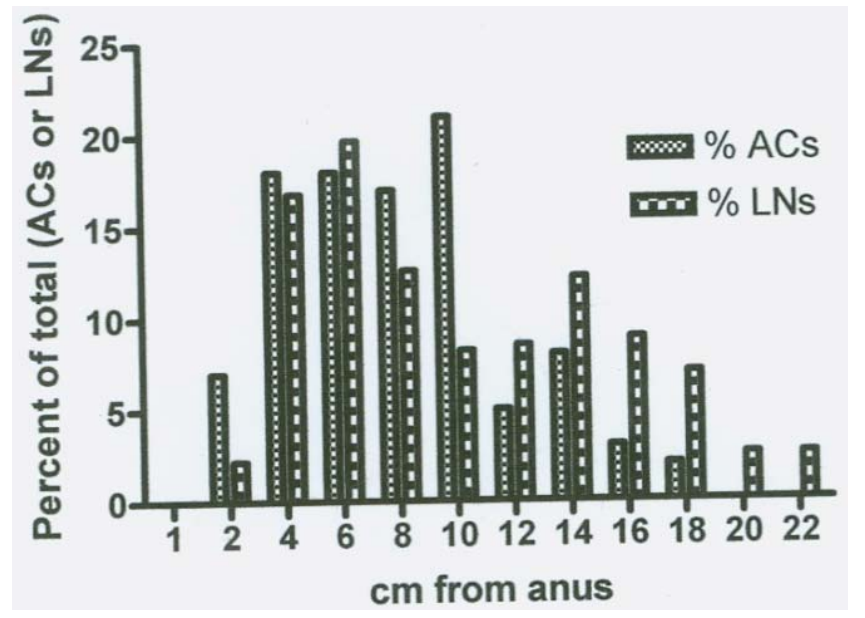

Fig. (5). Graph of the distribution of LN's and cancers at distances from the anal verge of humans. LN's and cancers occurred most frequently between 3.5 and $10 \mathrm{~cm}$ form the anal verge. Linear regression analysis reveals a significant correlation, $\mathrm{p}<0.01$, between cancer and LN frequency [38].

The results of these and other human studies give further credence to the conclusions derived from the animal studies by demonstrating that a significant positive linear relationship between numerical density of LN's and incidence of CRC occur in both animal models and humans.

\section{PROMOTIONAL ROLE OF LYMPHOID NODULES (LN's) IN THE FORMATION OF CRC}

That LN's have a promotion role in formation of CRC in DMH-treated rats is evident from the research of Hardman and Cameron [30]. A summary of their finding follows: The colonic crypt height and proliferative zone in crypts located over the aggregates of $\mathrm{LN}$ was significantly higher than in crypts located away from LN. This finding occurred in both DMH and non-DMH treated rats. Transforming growth factor alpha, a mitogenic factor, was found in the proliferation zone cells in crypts located over LN but not in crypts located away from LN. Crypts immediately adjacent to LN in humans demonstrate these same morphological features [3640].
Histological sections taken through the ALN of DMHtreated rats showed that $32 \%$ of them revealed presence of microscopic carcinoma either within or immediately adjacent to ALN (examples in Fig. 6) but in the same rats no microscopic carcinomas were observed in sections taken away from the ALN [27]. None of these microscopic cancers showed evidence of an adenomatous precursor nor was there any evidence of a lesion on the surface over the cancer. This observation provides evidence that these endophytic cancers arouse de novo.

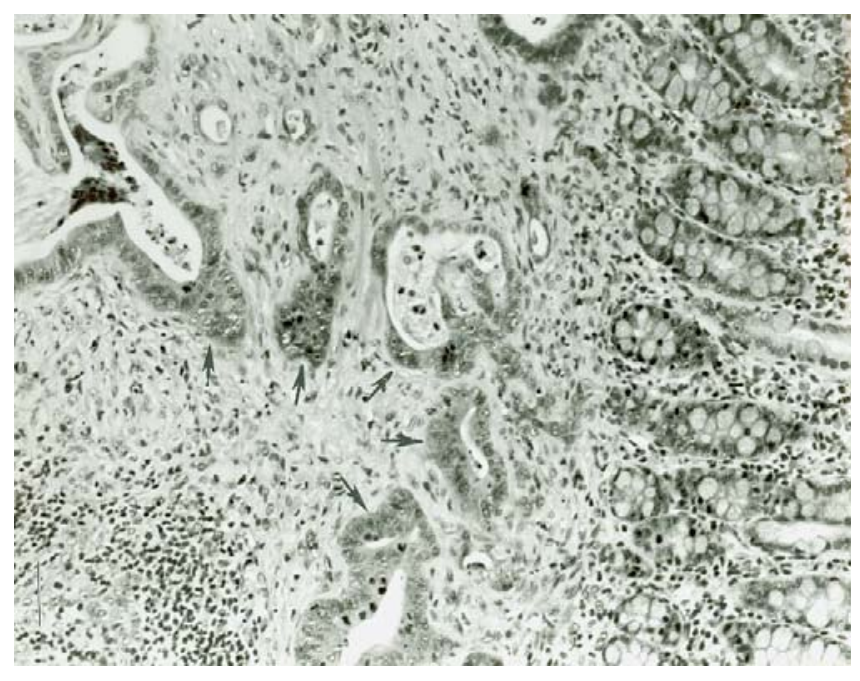

Fig. (6). Histological section of the large bowel wall of a rat treated with a large bowelcarcinogen [28]. Colon crypts are at right of this micrograph and a submucosal lymphoid nodule is at lower left. Arrows point to areas of submucosal carcinoma. The rat was injected with colchicine 3 hours prior to sacrifice to arrest dividing cells at metaphase (dark condensed chromatin area in cells). Notice that submucosal carcinoma cells closest to the nodule are taller and were more basophilic than the carcinoma cells further away from the lymphoid nodule.

Because ALN are consistently found in the same three sites along the length of the large bowel in rats that have not received the DMH carcinogen and because few LN occur elsewhere in the large bowel of the rats it is concluded that LN associated with CRC's were present before CRC developed and that the LN did not arise as an immune response to the CRC. This conclusion suggests that factors associated with $\mathrm{LN}$ are promotional to CRC in rats. Thus the specific anatomical location of LN's predetermines the distribution of CRC along the length of the large bowel of carcinogentreated rats and humans. This is not meant to imply that there is not an immunological reaction to the presence of a neoplasm [41].

The published reports from studies on carcinogeninduced $\mathrm{CRC}$ in rats and mice suggests a promotional role for LN's in CRC carcinogenesis [27-31, 36, 37].

What is the evidence that LN's promote formation of nonpolyploid or endophytic cancers?

As mentioned above Cameron et al. [33], using data published by Nauss et al. [31] on the distribution of polyploid and sessile-nonpolyploid cancers and of aggregates of LN's in DMH treated rat, revealed a significant linear relationship between number of sessile cancers and number of LN's but 
not of the number of the less frequently occurring polyploid cancer. Thus the nonpolyploid cancers but not polyploid cancers occurred significantly more frequently in regions of LN's than in regions away from LN's.

In humans a histopathological analysis of all nonpolyploid and polyploid cancers found presence of an $\mathrm{LN}$ in $36 \%$ of nonpolyploid neoplasias but in only $9 \%$ of polyploid neoplasias (Rubio 2000) [45]. Fu et al. [26] reported on the incidence and on the location of LN's of early colorectal neoplasms in 1,031 humans. Histological examination revealed a 3.2 fold significantly higher incidence of LN's in the left vs. the right large bowel. They also found that $80 \%$ of nonprotruding early CRC's associated with LN's were located under the muscularis mucosa (submucosal) while only $36 \%$ of protruding early CRCs associated with LN's were located over or across the muscularis mucosa (intramucosal). Thus $\mathrm{Fu}$ et al. present evidence in support of a significant correlation between the incidence of LN's and invasive tendencies of early CRC's in humans. Kobayaski et al. [46] have recently reviewed this subject. Their findings suggest $\mathrm{LN}$ are promotional to formation of the nonpolyploid-sessile-flat and depressed type cancers. Just how many of the CRC's in humans are of the nonpolyploid type and how many have developed by a nonadenomatous (de novo) pathway?

Table 2 summarizes literature on the reported incidence of nonpolyploid CRC's in humans [9, 23, 44-51]. The proportion of nonpolyploid CRC's ranges from 6.8 to $80 \%$ with a mean of $31 \%$. Goto et al. [25] attributes this wide range to differences in selection of subjects, sample size and the definition of nonpolyploid de novo cancers. Goto defines de novo cancers by the following criteria: absence of adenomatous component, all lateral margins covered by mucosa and a nonpolypoid or sessile growth pattern. Using these criteria Goto et al. [25], reported the incidence of de novo cancers in the following large bowel segments: Right $21 \%$, Left-rectum $18 \%$, and Rectum $32 \%$. Expressing these data as percent of de novo cancers per $\mathrm{cm}$ length gives the following value: Right $0.31 \%$, Left-rectum $0.272 \%$, Rectum $2.58 \%$. Expressed in this way indicates 8.3 to 9.6 times more de novo cancers per $\mathrm{cm}$ length in the rectum compared to the rest of the large bowel. This large difference emphasizes the importance of careful endoscopic screening for detection of de novo type cancers in the rectum.

Expressing human LN incidence data from Fig. (4) per $\mathrm{cm}$ length in the rectum compared to the rest of the large bowel indicates 5.2 times more LN's per $\mathrm{cm}$ in the rectum compared to the rest of the large bowel. Taking the rectal de novo cancer incidence data of Goto $\mathrm{et} \mathrm{al}$. and LN incidence data together suggests a promotional role of $\mathrm{LN}$ in the formation of de novo cancers.

A promotion effect of LN's on cancer development is illustrated in Fig. (6).

This histological section is from a de novo cancer from a rat treated with the large bowel carcinogen DMH [27]. The rat was injected with colchicine 3 hours before sacrifice. Colchicine arrests mitotic cells at metaphase and allows easy identification of areas of high cell proliferation in the histological section. Colon crypts are shown at the top of the figure and a submucosal lymphoid nodule is present at the bottom right part of the figure. The arrows point to submucosal carcinoma adjacent to the LN. Notice that carcinoma cells closer to the $\mathrm{LN}$ are larger and were more basophilic than those carcinoma cells further away from the LN. Also notice the high incidence of metaphase figures in the carcinoma cells located closer to the LN. These observations are interpreted to indicate that one or more paracrine LN derived growth factors is responsible for the promotion of the hyperplastic response on the carcinoma cells.

\section{Implications for CRC Endoscopic Screening and for CRC Prevention}

The finding presented in this report indicates that the first 14 to $19 \mathrm{~cm}$ of rectum up from the anus in humans is a site with an especially high rate of occurrence of cancer. The finding also indicates that high frequency of cancers that occur in the rectum can be linked to the high numerical density of LN's and to the promotional role of LN's on forma-

Table 2. Nonpolyploid Colorectal Cancers Expressed as Percent of Total Number

\begin{tabular}{|c|c|c|c|c|}
\hline Percent & Study site & Reference & Year & Number in study \\
\hline \hline $15 \%$ & Germany & Kiesslich et al. $[47]$ & 2007 & 100 \\
\hline $40 \%$ & France & Bedenne et al. [48] & 2006 & 1,630 \\
\hline $23 \%$ & Japan & Goto et al. [25] & 2010 & 14,817 \\
\hline $33 \%$ & Japan & Matsuda et al. [49] & 2003 & 6,638 \\
\hline$>30 \%$ & Taiwan & Chen et al. [50] & 1989 & 160 \\
\hline $80 \%$ & Japan & Shimoda et al. [51] & 2000 & 146 \\
\hline$>30 \%$ & UK & Rembacken et al. [52] & 2002 & 1,000 \\
\hline $46 \%$ & Brasil & Bromberg [9] & 1995 & 320 \\
\hline $22 \%$ & Germany & Stolte and Bethke [53] & 2002 & 150 \\
\hline $6.8 \%$ & Sweden & Tsuda et al. [54] & 2008 & 973 \\
\hline $9 \%$ & U.S. & Soetikno et al. [55] & 1,059 \\
\hline
\end{tabular}


tion of de novo cancers. The endoscopic detection of nonpolyploid/de novo CRCs presents a challenge. The challenge is to become proficient in endoscopic recognition of de novo cancers in order to remove them and to reduce CRC mortality rate. Use of new endoscopic techniques such as high magnification chromoscopic endoscopy (H-MCE) holds promise for distinguishing de novo (neoplastic) lesions from non-neoplastic lesions [53-57].

Given a promotional role of LN's on formation of CRC suggest that immunosuppressive measures might reduce the promotional effects of lymphoid nodules in the large bowel. Also given the high density of LN's in the rectum of human and their hyperplastic promotional role in CRC development one might predict that chronic administration of immunosuppressive drugs might selectively reduce risk of rectal cancer vs. nonrectal coloncancer that occurs elsewhere in the large bowel. Stewart et al. have indeed found that chronically immunosuppressed people do demonstrate a significant and selective reduction in incidence of rectal cancer (Table 3) [58]. It seems possible that long term use of immunosuppressive drugs may have suppressed CRC incidence via its anti-inflammatory action. In this regard it has been reported that regular use of aspirin, an anti-inflammatory drug, also reduces risk of CRC in humans and in animal models [59, 60]. It is suggested that effective CRC prevention strategies might specifically target suppression of the CRCpromotional activity of large bowel lymphoid nodules.

Table 3. Incidence of Gastric, Colon and Rectal Cancer in 73,076 Heart or Kidney Transplant Recipients ${ }^{\text {a }}$ (Stewart, T., et al., Clin. Cancer Res. 3:51, 1997)

\begin{tabular}{|c|c|c|}
\hline & Observed & Expected \\
\hline \hline gastric & $32^{\mathrm{b}}$ & 33 \\
\hline colon & $75^{\mathrm{b}}$ & 62 \\
\hline rectal & $15^{\mathrm{c}}$ & 42 \\
\hline
\end{tabular}

${ }^{a}$ Immunosuppression treatment drugs: cyclosporine, azathioprine, steroids.

${ }^{b}$ Not significantly different from expected.

${ }^{\mathrm{c}}$ Significantly different from expected and the protection was greater in men than in women.

\section{ACKNOWLEDGEMENTS}

I dedicate this report to six of my former graduate and post-doctoral students whose research has contributed to the subject of this report. They are: Elaine Hardman, David Heitman, John Carter, Chris Barnes, James Kent and J.Y. Luh. The assistance of Kerri Glaspie and Joseph Moreno with manuscript preparation is gratefully acknowledged.

The past support of the following agencies is gratefully acknowledged:

American Cancer Society, American Institute for Cancer Research, and the National Cancer Institute.

\section{CONFLICT OF INTEREST}

None Declared.

\section{REFERENCES}

[1] Morgenstern L, Lee SE. Spatial distribution of colonic carcinoma. Arch Surg 1978; 113: 1142-43.
[2] Chattar-Cora D, Omime CD, Coppa GF, Valentine IS, Rivera L. Anatomic, age, and sex distribution of colorectal cancer in a New York City Hispanic population. J Natl Med Assoc 1978; 90: 19-24.

[3] Fleshner P, Slater G, Aufses AH. Age and sex distribution of patients with colorectal cancer. Dis Colon Rectum 1989; 32: 107-11.

[4] Shellnut K, Wasvary HJ, Grodsky B, Boura A, Priest G. Evaluating the Age distribution of patients with colorectal cancer: are the Unites States preventative services task force guidelines for colorectal cancer screening appropriate? Dis Colon Rectum 2010; 53: $5-8$.

[5] Cooper GS, Yuan SC, Landefeld M, Johnson F, Rimm A. A national population- based study of incidence of colorectal cancer and age. Cancer 1995; 75: 775-81.

[6] Qing SH, Rao KY, Jiang HJ, Wexner SD. Radical differences in the anatomical distribution of colorectal cancer: a study of differences between American and Chinese patients. World J Gastroenterol 2009; 9: 721-5.

[7] Wu Z, Vivien W, Chen JM, et al. Subite-Specific colorectal cancer incidence rates and stage distributions among Asians and Pacific Islanders in the United States. Cancer Epidemiol Biomarker Prev 2004; 13: 1215-22.

[8] Cancer Facts, Colorectal cancer subsite distribution differs by sex Cancer statistics. Ontario,Canada 2010.

[9] Bromberg SH, Barreto E, Godoy AC. Clinical and macroscopic variables that influence the prognosis of colorectal carcinoma. Arg Gastroenterol 2002; 163: 72 .

[10] McFarlene ME, Rhoden A, Fletcher PR, Carpenter R. Cancer of the colon and rectum in a Jamaican population: diagnostic implications of the changing frequency and subsite distribution. West Indian Med J 2004; 53: 170-3.

[11] Gomez D, Dahal Z, Raw E, Roberts C, Lyndon PJ. Anatomical distribution of colorectal cancer over a 10 year period in a district general hospital; is there a true "rightward shift"? Postgrad Med J 2004; 80: 667-9.

[12] Crerand S, Freely, TM, Waldran RP, et al. Colorectal carcinoma over 30 years at one hospital: no evidence of a shift to the right. Int J Colorectal Dis 1991; 6: 184-7.

[13] McCallion K, Mitchell RMS, Wilson RH, et al. Flexible sigmoidoscopy and the changing distribution of colorectal cancer: implications for screening. Gut 2001; 48: 522-5.

[14] vanRossum LGM, van Rijin AF, van Munster IP, et al. Earlier stages of colorectal cancer detected with immunochemical faecal occult blood tests. Netherlands J Med 2008; 67: 182-6.

[15] Eide TJ. The age, sex, and site-specific occurrence of adenomas and carcinomas of the large intestine within a defined population.Sean. J Gastro 1986; 21: 1083-88.

[16] Mensink PBF, Kolkman JJ, Baarlen J, Kleibeuker J. Change in anatomic distribution and incidence of colorectal carcinoma 2002; 45: 1393-6.

[17] PonzdeLeon M, Marino M, Benatti $\mathrm{P}$, et al. Trend of incidence, subsite distribution and staging of colorectal neoplasms in the 15year experience of a specialized cancer registry. Annals Oncol 2004; 15: 940-6.

[18] Abdulkareem FB, Faduyil FA, Daramola AO, et al. Malignant gastrointestinal tumours in South Western Nigeria: a histopathologic analysis of 713 cases. West Afr J Med 2009; 28: 173-5.

[19] Odigia VI, Yusufu LM, Dawotola DA, et al. Anatomical subsite and diagnostic implications of colorectal cancer in zaria (Guinea savannah)-1981-2005. Niger Postgrad Med J 2009; 16: 35-9.

[20] Nikshoar R, Saghebi R, Shakiba M. Evaluation of age, sex and anatomical distribution of 2107 operated colorectal cancer in Iran. UICC World Cancer Congress 2006.

[21] Deo SV, Shukla NK, Shinivas G, et al.Colorectal cancersexperience at a regional cancer center in India. Trop Gastroentenci 2001; 22: 83-6.

[22] Peedikayil MC, Nair P, Seena SM, et al. Colorectal cancer distribution in 220 Indian patients undergoing colonoscopy. Indian J Gastroenterol 2009; $28: 212-5$.

[23] Jass, JR. Subsite distribution and incidence of colorectal cancer in New Zealand. 1974-1983. Dis Colon Rectum 1991; 34: 56-9.

[24] Sakamoto N, Terai T, Ohkusa T, et al. Distribution comparison of depressed vs. non-depressed early colorectal cancers. Ailment Pharmacol Thersymp ser 2006; 2: 227-32.

[25] Goto H, Oda Y, Murakami Y, et al. Proportion of de novo cancers among colorectal cancers in Japan. Gastroenterol 2006; 131: 404-6. 
[26] Fu KL, Sano Y, Kato S, et al. Incidence and localization of lymphoid follicles in early colorectal neoplasms. World J Gastroenterol 2005; 11: 6863-66.

[27] Leng Q, Wu KL, Jin HY, et al. Distribution characteristircs of colorectal neoplasm in 4450 patients and implication for colorector cancer screening. Zhonghua Wei Chang WaiKeZaZhi 2010; 13: $822-4$.

[28] Kim DH, Shin MH, Ahn YO. Incidence pattern of colorectal cancer in Korea by subsite of origin. J Korean Med Sci 2000; 15: 675-81.

[29] Shieh J, Wong M, Wang YI. Site distribution of colorectal cancer: a retrospective study of 1198cases. Chinese J Gastroenterol1990; 7: 116-21.

[30] Hardman WE, Cameron IL. Colonic crypts located over lymphoid colon nodules of 1.2-dimethylhydrazine-treated rats are hyperplastic and at high risk of forming adenocarcinomas. Carcinogenesis 1994; 15: 2353-61.

[31] Nauss KM, Locniskar M, Newberne PM. Morphology and distribution of 1.2-dimethylhydrazine dihydrochloride-induced colon tumors and their relationship to gut-associated lymphoid tissues in rats. J Natl Cancer Inst 1984; 73: 915-21.

[32] Sunter JP, Appleton DR, Wright NA, Watson AJ. Pathological features of the colonic tumors induced in rats by the administration of 1.2-dimethylthydrazine. Virchows Arch B Cell Pathol 1978; 29: 211-3.

[33] Cameron IL, Garza J, Hardman WE. Distribution of lymphoid nodules, aberrant crypt foci and tumours in the colon of carcinogen-treated rats. Br J Cancer 1996; 73: 893-8.

[34] Carter JW, Lancaster HK, Hardman WE, Cameron IL. Distribution of intestine-associated lymphoid tissue, aberrant crypt foci, and tumors in the large bowel of 1.2-dimethylhydrazine-treated mice. Cancer Res 1994; 54: 4304-7.

[35] de Jong UW, Day NE, Muir CS. The distribution of cancer within the large bowel. Internat J Cancer 1972; 10: 463-77.

[36] Langman JM, Rowland R. The number of distribution of lymphoid follicles in the large intestine. J Anat 1986; 194: 189-94.

[37] Cameron IL, Kent JE, Philo R, Barnes CJ, Hardman WE. Numerical distribution of lymphoid nodules in the human sigmoid colon, rectosigmoidal junction, rectum, and anal canal. Clin Anat 2006; 19: 164-70.

[38] Luh JY, Hardman WE, Cameron IL, Wang SJ, Thomas CR. Link between rectal cancer (RC) Location and spatial numerical distribution of lymphoid nodules $(\mathrm{LN})$ in the human rectum. I.J. Radiation Oncology 2006; S268-9.

[39] Hamman A, Arveux P, Martin M. Effect of gut-associated lymphoid tissue on cellular proliferation in proximal tissue on cellular proliferation in proximal and distal colon of the rat. Dig Dis Sci 1992; 37: 1099-104.

[40] Martin MS, Hamman A, Martin F. Gut-associated lymphoid tissue and 1.2 dimethylhydrazine intestinal tumors in the rat: an histological and immunoenzymatic study. Int J Cancer 1986; 38: 75-80.

[41] Shamsuddin AKM, Trump BF. Colon epithelium. II. In vivo studies of colon carcinogenesis: light microscopic, histochemical and ultrastructural studies of histogenesis of azoxymethane-induced colon carcinoma in Fischer 344 rats. J Natl Cancer Inst 1981; 66: 389-93.

[42] Shamsuddin JKM, Hogan ML. Large intestinal carcinogenesis. II. Histogenesis and unusual features of low-dose azoxymethaneinduced carcinomas in f344 rats. J Natl Cancer Inst 1984; 73: 1297305 .
[43] Glick SN, Teplick SK, Ross WM. 1988 Colonic lymphoid follicle associated with colonic neoplasms. Radiology 1988; 168: 603-7.

[44] McMullen TPW, Lai R, Dabbaugh L, Wallace TM, de Garza CJ. Survival in rectal cancer is predicted by $\mathrm{T}$ cell infiltration of tumour-associated lymphoid nodules. Clin Exp Immunol 2010; 161: 81-8.

[45] Rubio CA. Nonprotruding colorectal neoplasms: epidemiologic viewpoint. World J Surg 2000; 24: 1098-103.

[46] Kobayashi N, Matshda T, Sano Y. The natural history of nonpolyploid colorectal neoplasms. Gastrointest Endoscop Clin North Am 2010; 20: 431-5.

[47] Kiesslich R, Goetz M, Vieth M, Galle PR, Neurath MF. Technology insight: confocal laser endoscopy for in vivio diagnosis of colorectal cancer. Nat Clin Pract Oncol 2007; 4: 480-90.

[48] Bedenne L, Faivre J, Boutron MC, et al. Adenoma-carcinoma sequence or "de novo" carcinogenesis? a study of adenomatous remnants in a population-based series of large bowel cancers. Cancer 1992; 69: 883-8.

[49] Matsuda T, Saito Y, Hoita K, Sano Y, Fujii T. Prevalance and clinicopathological features of nonpolypoid colorectal neoplasms: Should we pay more attention to identifying flat and depressed lesions? Digestive Endoscopy 2010; 22(Suppl 1): 557-62.

[50] Chen CS, Yen MF, Wang Wm, et al. A case-cohort study for the disease history of adenoma-carcinoma and de novo carcinoma and surveillance of colon and rectum after polypectomy: implications for efficacy of colonoscopy. Br J Cancer 2003; 88: 1866-73

[51] Shimoda T, Ikegami M, Fujisaki J, et al. Early colorectal carcinoma with special reference to its development de novo. Cancer 1989; 64: 1138-46.

[52] Rembacken BJ, Fujii T, Cairns A, et al. Flat and depressed colonic neoplasms: a prospective study of 1000 coloscopies in the UK. Lancet 2000; 355: 1211-14.

[53] Stolte M, Bethke B. Colorectal mini-de novo carcinoma: a reality in Germany too. Endoscopy 1995; 27: 286-90.

[54] Tsuda S, Veress B, Toth E, et al. Flat and depressed colorectal tumors in a southern Swedish population: a prospective chromoendoscipic and histopathological study. Lancet 2000; 355: 1211-4.

[55] Soetikno PM, Kaltenbach T, Rouse RV, et al. Prevalance of nonpolypoid (flat and depressed) colorectal neoplasms in asymptomatic and symptomatic adults. JAMA 2008; 299: 1027-35.

[56] Hurlstone DP. Early colorectal cancer detection - Confocal endomicroscopy and other novel endoscopic techniques. Eur Gastroenterol Rev 2007; 60-3.

[57] Hurlstone DP, Cross SS, Adam I, et al. Efficacy of high magnification chromoscopic colonoscopy for the diagnosis of resplexia in flat and depressed lesions of the colorectum: a prospective analysis. Gut 2004; 53: 284-90.

[58] Hurlstone DP, Fujii T. Practical uses of chronoendoscopy and magnification at colonoscopy. Gastroest Endos Cin N Am 2005; 15: 687-702.

[59] Hurlstone DP, Fujii T, Luhr AL. Early detection of colorectal cancer using high-magnification chronoscopic colonoscopy. Br J Surg 2002; 89: 272-82.

[60] Kudo S. Nonpolypoid neoplastic lesions of the colorectal mucosa. Gastrointestinal Endoscopy 2008; 68(45). 